\title{
Os Sintomas Psicofuncionais e a Relação Mãe-Bebês Gêmeos aos Nove Meses de Idade
}

\author{
Mariléia Orn Scalco ${ }^{1}$ \\ Tagma Marina Schneider Donelli \\ Programa de Pós-Graduação em Psicologia Clínica da Universidade do Vale do Rio \\ dos Sinos, São Leopoldo, Rio Grande do Sul, Brasil
}

\begin{abstract}
Resumo
Os sintomas psicofuncionais manifestados pelo bebê se refletem no comportamento disfuncional da criança e se manifestam nas áreas relacionadas ao sono, alimentação, digestão, respiração, pele e comportamento. A literatura aponta para a existência de uma relação entre a presença de tais sintomas no bebê e a dinâmica da relação deste com a mãe. A partir de uma perspectiva psicanalítica, a presente pesquisa, de caráter exploratório e abordagem qualitativa, utilizou o delineamento de estudo de caso único para investigar a relação mãe-bebês, em situação de gemelaridade, cujos bebês apresentam indicadores de sintomas psicofuncionais aos nove meses de idade. Participaram deste estudo uma tríade formada pela mãe e seus bebês gêmeos com idade de nove meses. Os instrumentos utilizados foram o Symptom Check-List, uma ficha de dados sócio-demográficos, entrevista semi-estruturada com a mãe e sessão de observação da interação livre da mãe com os bebês. Os resultados apontam que a gemelaridade pode configurar-se como um dos fatores que pode aumentar as chances do surgimento dos sintomas psicofuncionais em fase precoce do desenvolvimento. Além disso, a conflitiva conjugal aliada à falta de apoio paterno, em especial em situação de gemelaridade, pode potencializar as chances de surgimento de falha materna e consequente risco ao desenvolvimento de sintomas psicofuncionais nos bebês. Desta forma, ampliar a compreensão acerca do funcionamento de uma tríade pode contribuir como medida preventiva e fornecer subsídios para profissionais de diversas áreas de atuação que trabalham com bebês e suas mães como escolas, hospitais, clínicas e psicoterapeutas da relação pais-bebê.
\end{abstract}

Palavras-chave: Relação mãe-filho, gemelaridade, sintomas psicofuncionais.

\section{Symptoms Psychofunctional and the Mother-Twin Babies at Nine Months of Age}

\begin{abstract}
The symptoms manifested by psychofunctional baby are reflected in the child's dysfunctional behavior and manifested in the areas related to sleep, feeding, digestion, respiration, skin and behavior. The literature points to the existence of a relationship between the presence of such symptoms in the baby and the dynamics of its relationship with the mother. From a psychoanalytic perspective, this research, exploratory and qualitative approach, we used the design of a single case study to investigate the mother-infant in situation of twins, whose babies have symptoms indicators psychofunctional nine months age. The study included a triad formed by the mother and her twin babies aged nine months. The instruments used were the Symptom Check List, a form of socio-demographic data, semi-structured interview with
\end{abstract}

Endereço para correspondência: Av. Borregaard, 275, Altos Alegria, Guaíba, RS, Brasil 92500-000. E-mail: marileia.scalco@gmail.com e tagmapsi@gmail.com 
the mother and observing session of free interaction of mothers with babies. Results show that the twins can set up as one of the factors that can increase the chances of the onset of symptoms psychofunctional in early stage of development. Moreover, the conflictive marital coupled with lack of parental support, especially in situations of multiple births, can enhance the chances of emergence of maternal failure and consequent risk to develop symptoms in babies psychofunctional. Thus, increasing the understanding of the functioning of a triad can contribute as a preventive measure and provide subsidies for professionals from various fields of expertise who work with babies and their mothers as schools, hospitals, clinics and therapists of parent-infant relationship.

Keywords: Mother-child relations, child psychopathology, twinning.

\section{Los Síntomas Psicofuncionales y los Bebés Gemelos de Madre a los Nueve Meses de Edad}

\section{Resumen}

Los síntomas se manifiestan por psicofuncionales bebé se reflejan en el comportamiento disfuncional del niño y que se manifiesta en los ámbitos relacionados con el sueño, la alimentación, la digestión, la respiración, la piel y el comportamiento. La literatura apunta a la existencia de una relación entre la presencia de tales síntomas en el bebé y la dinámica de su relación con la madre. Desde una perspectiva psicoanalítica, la investigación, el enfoque exploratorio y cualitativo, se utilizó el diseño de un estudio de caso único para investigar la relación madre-niño en situación de gemelos, cuyos bebés tienen indicadores de síntomas psicofuncionales nueve meses edad. El estudio incluyó una tríada formada por la madre y sus bebés gemelos de nueve meses. Los instrumentos utilizados fueron la Lista de verificación de síntomas, una forma de datos sociodemográficos, semi-estructurada entrevista con la madre y la sesión de observación de la libre interacción de las madres con bebés. Los resultados muestran que los gemelos pueden establecerse como uno de los factores que pueden aumentar las probabilidades de la aparición de los síntomas psicofuncionales en la etapa inicial de desarrollo. Por otra parte, el acoplado conflictivo matrimonio con la falta de apoyo de los padres, especialmente en situaciones de nacimientos múltiples, puede aumentar las posibilidades de aparición de insuficiencia materna y el consiguiente riesgo de desarrollar síntomas en los bebés psicofuncionales. Por lo tanto, el aumento de la comprensión del funcionamiento de una tríada puede contribuir como una medida preventiva y proporcionar subvenciones para profesionales de diversas áreas de conocimiento que trabajan con bebés y sus madres como escuelas, hospitales, clínicas y terapeutas de la relación padre-hijo.

Palabras clave: Madre-hijo, twins, psicofuncionales síntomas.

O nascimento de um bebê possibilita o nascimento de uma dupla parental e produz no seio familiar um contexto de relações bastante complexo, no qual cada integrante deste grupo lidará com a situação de maneira muito particular (Cunha, 2004; Oliveira, 2002). A mulher ocupa papel fundamental neste contexto, pois ao se tornar mãe, empreenderá um trabalho reflexivo sobre seu papel e sua capacidade de ocupar este lugar, revivendo seu papel de filha para absorver o papel de mãe deste bebê, o que irá se refletir na qualidade dos cuidados parentais dirigidos ao filho, contribuindo para a formação da estrutura psíquica da criança.

Durante os anos iniciais do desenvolvimento psíquico, a questão do ambiente se resume praticamente à situação de relacionamento entre mãe e filho. O bebê que ainda não está constituído psiquicamente, requer que o ambiente - de modo preferencial a mãe - apresente condições suficientes de continência que lhe proporcionem a experiência de plenitude e de sustentação. Quando a mãe oferece tais condições, o bebê pode se desenvolver e se separar dela, usando 
o relacionamento mãe-filho como um veículo para a formação de sua própria identidade. Entretanto, torna-se um desafio ainda maior oferecer tais condições no caso de gêmeos, já que a mãe precisa atender a demanda de dois bebês com necessidades diferentes e que formarão personalidades também diferentes (Gorayeb, 1985; Robin, Corroyer, \& Casati, 1996; Winnicott, 1960/1990).

Um estudo que se preocupou com a relação mãe-bebês gêmeos evidenciou que a qualidade do vínculo parental influi no desenvolvimento dos gemelares durante o primeiro ano de vida, destacando que eles necessitam ser nutridos afetivamente por cuidadores adultos. Observaram-se escassas interações dos gêmeos entre si durante o período do estudo, reforçando a importância das relações com os cuidadores (Lucion \& Escosteguy, 2011).

Desta forma, entende-se que a relação mãe-bebê se reflete no desenvolvimento infantil sob diversos aspectos. Desde a concepção, mães e bebês participam de um sistema muito intenso em suas relações, o qual emerge, se organiza e se modifica através da evolução e de eventos culturais atravessados ao desenvolvimento subseqüente de ambos (Zamberlan, 2002). Neste contexto, as ações recíprocas que derivam das relações objetais intrapsíquicas caracterizam-se como trocas interativas que revelam a natureza do que pode ser chamado de apego na relação da dupla (Cramer \& Palácio-Espasa, 1993). O estudo desta troca permite apreender a receptividade do parceiro, o significado atribuído à solicitação e, de modo geral, a natureza da comunicação estabelecida na díade.

A qualidade das interações na fase inicial da vida, entre o bebê e seu cuidador em diferentes contextos, tem implicações significativas, do ponto de vista clínico. As perturbações destas interações constituem, muitas vezes, um dos primeiros indícios de dificuldades em vias de instalação no bebê (Wendland, 2001). Os conteúdos mentais que ainda não podem ser processados pelo aparelho psíquico do bebê buscam descarga emocional através da via corporal (Edelstein, 2000). Sendo assim, o bebê se caracteriza por uma unidade, por excelência, psicossomática, dada por sua própria condição humana. Na medida em que o psiquismo vai amadurecendo e se estruturando, ocorre uma diminuição das manifestações somáticas.

Neste sentido, quando a criança apresenta um sintoma que coloca em risco a sua constituição psíquica, este sofrimento aparece no seu funcionamento corporal, é um sintoma "dado a ver", diferentemente do adulto que tem condições de expressar seus sentimentos em palavras e atitudes (Jerusalinsky \& Berlinck, 2008). O bebê ainda não adquiriu a capacidade de simbolização e este sofrimento é demonstrado através do corpo (Klein, 1952/1982).

Conforme Kreisler (1978), um dos pioneiros no estudo da psicopatologia da criança pequena, a expressão somática ocupa posição de destaque na psicopatologia do bebê, tendo em vista o fato de atingir as principais funções: sono, alimentação, eliminação e respiração. Trata-se, portanto, de uma patologia principalmente funcional em que o corpo é o lugar pelo qual a criança em conflito exprime sua insatisfação.

Desta forma, o corpo desempenha papel central, representando uma via real de acesso aos processos de simbolização e subjetivação. Esses processos ganham importância também no contexto das interações precoces vividas pela criança, dando lugar a uma atividade de mentalização e figuração essencial na formação do aparelho psíquico do bebê (Golse, 2004; Winnicott, 1960/1990).

Neste cenário, os sintomas psicofuncionais que aparecem aliados a sua relação com a qualidade dos vínculos primários e o interesse pelo assunto tem se ampliado nas últimas décadas e se difundido através de artigos científicos no Brasil e exterior (Pinto, 2004). A gênese destes fenômenos psicossomáticos encontra-se, de acordo com a literatura psicanalítica, na dinâmica estabelecida na primeira infância entre o bebê e seu cuidador, frequentemente a mãe (Oliveira, 2002).

Os sintomas psicofuncionais podem ser definidos como manifestações de natureza principalmente somática e do comportamento da criança, sem uma causa orgânica definida e que podem indicar dificuldades na interação mãe-be- 
bê ou pais-bebê, podendo ser compreendidos, até mesmo, como sintoma de relação, evidenciando a estreita relação entre o psíquico e o somático. Os sintomas psicofuncionais mais comuns, que aparecem no início da vida, são relacionados às seguintes áreas: sono, alimentação, digestão, respiração, pele e comportamento (Pinto, 2004; Robert-Tissot et al., 1989).

Observa-se que a problemática relacionada ao comportamento, às dificuldades de relacionamento e à sintomatologia precoce representam, ainda, uma lacuna na literatura científica atual. $\mathrm{O}$ tema aborda um campo de estudo relativamente recente e, as poucas pesquisas encontradas nas bases de dados, investigam apenas um aspecto específico da sintomatologia. Nas raras vezes em que a sintomatologia precoce é abordada, os estudos são predominantemente teóricos, realizados através de revisão de literatura, o que denota carência de estudos que realizem pesquisas empíricas dentro desta temática (Tenenbojm, Rossin, Estivill, Segarra, \& Remião, 2010).

A literatura científica a respeito da relação mãe-criança relacionada ao contexto da sintomatologia precoce ainda é escassa. Nesse sentido, a deteç̧ão precoce de problemas na primeira infância e a consequente dificuldade no diagnóstico também revelam um campo de pesquisa pouco explorado. A maioria dos estudos enfoca apenas um aspecto da sintomatologia como, por exemplo, o transtorno alimentar (Vendruscolo, Bolzan, Crestani, Souza, \& Moraes, 2012) e o transtorno respiratório (Oliveira, 2002).

Mais especificamente, existem poucos estudos acerca da relação precoce mãe-gêmeos e a crescente incidência de gestações gemelares evidencia a importância de um estudo com essa temática. Foram encontrados poucos estudos enfocando aspectos da relação entre mãe e filhos gêmeos (Bochernitsan, 2012; David, Azevedo, Russi, Berthoud, \& Oliveira, 2000; Lucion \& Escosteguy, 2011). Grande parte das pesquisas enfoca os mais diversos temas relacionados a gemelaridade em fases mais adiantadas do desenvolvimento como situações edípicas (Tavares, 2007), subjetividade e narcisismo (Marquez, 2008), dificuldades de conduta na educação infantil (D’Onofrio et al., 2007), depressão pa- rental (Singh et al., 2011), gêmeos abrigados (Careta, 2006), QI e desfechos de vida (Nedelec, Schwartz, Connolly, \& Beaver, 2012), práticas de socialização (Vieira \& Uchoa, 2010), superdotação (Passos \& Barbosa, 2011), entre outros.

Desta forma, esta pesquisa pretende aprofundar o conhecimento acerca da relação mãe-bebê em fase precoce do desenvolvimento, além de contribuir para compreender quais aspectos da relação mãe-bebê, em especial em situação de gemelaridade, podem estar envolvidos na manifestação de sintomatologia nos bebês, visto que a organização psicopatológica precoce remete a condições relacionais, também precoces (Kreisler, 1978; Lebovici, 1999). Nesta perspectiva, esta pesquisa teve por objetivo investigar a relação mãe-bebês, em situação de gemelaridade, cujos bebês apresentaram indicadores de sintomas psicofuncionais aos 9 meses de idade.

\section{Método}

\section{Delineamento}

Foi utilizado nesta pesquisa um estudo de caso único no qual foram analisados a mãe e seu casal de filhos gêmeos configurando uma tríade mãe-bebês, segundo o modelo de estudo de caso proposto por Yin (2005).

\section{Participantes}

Participaram deste estudo uma tríade formada por uma mãe e seu casal de filhos gêmeos, que buscaram atendimento médico em uma Unidade Básica de Saúde da região Metropolitana de Porto Alegre. A mãe tinha 27 anos, ensino médio incompleto e não tinha relacionamento estável com o pai das crianças, do qual separou-se quando estava no quinto mês de gestação. No momento da coleta de dados ela não estava trabalhando e dependia da aposentadoria da mãe para seu sustento e de seus filhos, incluindo filho mais velho de 8 anos. O pediatra indicou para esta pesquisa apenas o bebê do sexo masculino, por este apresentar um histórico de dificuldades respiratórias. Durante a coleta de dados, a pesquisadora identificou a presença de dificuldades alimentares na menina, irmã gêmea do menino. 


\section{Procedimentos e Instrumentos}

Primeiramente, a pesquisa foi aprovada por Comitê de Ética em Pesquisa vinculado ao CONEP (Comissão Nacional de Ética em Pesquisa), respeitando todos os princípios éticos para pesquisa em Psicologia com Seres Humanos contidos na resolução $n^{\circ} 016 / 2000$, do Conselho Federal de Psicologia (CFP) e do Conselho Nacional de Saúde, resolução ${ }^{\circ}$ 196/1996. Em seguida, foi realizado contato com pediatras de municípios da região metropolitana de Porto Alegre para apresentar os objetivos e a proposta do presente estudo. O pediatra que concordou em participar desta pesquisa solicitou que a pesquisadora o acompanhasse em seus atendimentos de puericultura que aconteciam em horários pré-definidos, a fim de localizar os possíveis participantes deste estudo.

A mãe participante deste estudo foi localizada, inicialmente, neste acompanhamento de consulta. Após a concordância em participar do estudo, foi agendado o encontro presencial na residência da família, com o objetivo de explicitar a proposta, os objetivos e procedimentos do estudo. Com a confirmação do interesse em fazer parte desta pesquisa, a mãe assinou um Termo de Consentimento Livre e Esclarecido (TCLE), como previsto nos procedimentos éticos.

Nesse contato foi preenchida a ficha de dados sócio-demográficos e realizada a aplicação do questionário "Symptom Check-List" (Robert-Tissot et al.,1989) para identificar quais sintomas psicofuncionais estavam presentes no bebê indicado pelo pediatra. Neste momento percebeu-se, através do discurso da mãe, que a irmã gêmea do menino evidenciava a presença de transtorno alimentar e foi solicitado autorização da mãe para que o estudo fosse realizado com a participação das duas crianças. Com a concordância da mãe, aplicou-se o questionário "Symptom Check-List" para identificar a presença de sintomas na menina. Mais tarde, foi realizada a entrevista semi-estruturada sobre a gestação, o parto, os primeiros meses de vida dos bebês e aspectos atuais do relacionamento mãe-bebês, que foi gravada e transcrita logo após sua ocorrência.

Por fim, ocorreu a sessão de observação da interação livre da mãe com os bebês, que foi posteriormente relatada. Todas as etapas foram realizadas em um único dia em função da dificuldade de acesso ao local e da disponibilidade da mãe, que preferiu realizar as etapas em um único encontro.

\section{Resultados e Discussão}

Todo o material foi analisado e interpretado a partir do referencial teórico psicanalítico, que versa a respeito da relação mãe-bebê e dos sentimentos referentes à sintomatologia precoce manifestada no primeiro ano de vida, além de pesquisas que abordam a temática na contemporaneidade.

O caso foi construído procurando integrar os resultados obtidos com a aplicação dos instrumentos. Para a análise dos dados, inicialmente as respostas do Symptom Check-list foram codificadas conforme protocolo e roteiro próprios do instrumento. A codificação baseia-se em três dimensões para cada sistema (sono, alimentação, digestão, respiração, pele e comportamento) a ser avaliado, são elas: (a) variações dentro do normal; (b) tensões significativas, com alguma desarmonia na regulação da tarefa e (c) sistema claramente disfuncional. O roteiro do instrumento aponta que quanto maior a pontuação obtida nas respostas mais disfuncional é o sistema que está em avaliação. Essas respostas auxiliaram na construção do estudo deste caso, visando compreender e aprofundar a temática em questão. Os dados levantados na ficha de dados sócio-demográficos foram considerados como complementares para a contextualização e entendimento do caso. A observação do momento de interação livre mãe-bebês foi analisada qualitativamente, contribuindo para a construção do caso e o aprofundamento da compreensão deste. A entrevista com a mãe foi gravada e posteriormente transcrita literalmente. $\mathrm{O}$ material foi analisado em uma tentativa de compreensão individual das singularidades do caso.

A partir destes dados o caso foi organizado em quatro eixos de compreensão, que são: I- o período pré-natal e o parto; II- o puerpério; IIIrelação mãe-bebês; e IV- sintomas apresentados pelos bebês. A exposição dos temas foi apresen- 
tada respeitando a cronologia dos acontecimentos. Ao longo dos resultados e discussões o nome da mãe e dos bebês, bem como informações adicionais que possibilitassem a identificação dos participantes deste estudo, foram alterados a fim de respeitar o sigilo.

Como se trata de um estudo qualitativo, que reconhece o pesquisador como sujeito ativo da pesquisa, as impressões do entrevistador também foram descritas e consideradas como dados complementares para a análise e compreensão dos casos estudados e dos resultados da pesquisa. Integrada aos resultados está apresentada a discussão que consistiu em analisar os fenômenos exaustivamente, buscando articular a revisão teórica com os fatos levantados com os instrumentos da pesquisa.

\section{Descrição do Caso}

Gabriela, 27 anos, ensino médio incompleto, solteira, reside atualmente com sua família de origem: mãe, irmão, cunhada, seu filho de oito anos e os bebês de nove meses de idade. É importante destacar que a mãe que Gabriela refere é, na verdade, sua avó paterna, e que, desde criança, ela acreditava que esta avó era sua mãe biológica. Ela morou com o pai dos bebês por cerca de oito meses, contra a vontade de sua família. Nesse período, deixou seu filho mais velho com a mãe/avó, repetindo a atitude que sua mãe biológica teve em relação a ela.

Eixo I - O Período Pré Natal e o Parto. Após três meses residindo com o namorado descobriu, através de um teste de farmácia, que estava grávida. Refere ter ficado muito assustada, chateada e até mesmo depressiva com a novidade, já que não houve um planejamento prévio desta gestação.

A descoberta de que seriam gêmeos se deu com quatro meses. $\mathrm{O}$ pai das crianças estava a acompanhando durante o exame, e conta que sentiu-se apavorada, descrevendo o momento como sendo um susto, levou um tempo pra se acostumar:

Ai o médico disse, "o que é eu não sei, mas vou sublinhar aqui esses dois pontinhos aqui, são duas crianças, de placentas separadas, são bivitelinos". Ai eu fiquei, deita- da, não sabia se eu chorava, se eu ria, e foi um susto né... mas ao mesmo tempo pensei né: (PQP...), dois? Se é pra ser vai ser, não adianta, ninguém carrega uma cruz que não pode carregar, mas levou um tempinho pra eu me acostumar...

Conforme Winnicott (1945/2012), caso as mães pudessem escolher se gostariam ou não de ter filhos gêmeos, a maioria faria a opção de não tê-los na forma de gêmeos, sugerindo as dificuldades dessa situação. Ainda que a ocorrência do nascimento de gêmeos exerça fascinação sobre as pessoas, por outro lado esta revelação pode trazer consigo um aumento de ansiedade e angústia pela dúvida gerada a respeito da forma adequada de pensar sobre e lidar com os filhos gêmeos (David et al., 2000).

Percebe-se que, no caso estudado, a gravidez foi um período bastante conflituoso no relacionamento do casal, que veio a se separar quando Gabriela estava no quinto mês de gestação. As questões da gravidez propriamente dita e da gemelaridade podem ter sido secundárias ao sofrimento da mãe com a situação conjugal, permeada por traição e abandono, dado que se confirma em função do fato da mãe, quando questionada sobre a gestação, se referir somente ao conflito conjugal: era preciso refazer a pergunta uma ou duas vezes para que ela falasse dos sentimentos para com seu estado gestacional. Gabriela parece não ter tido tempo e nem disponibilidade psíquica para direcionar seu pensamento em imaginar e personalizar estas crianças durante sua gestação, abrindo espaço para eles em sua vida e no seu imaginário, em função de toda conflitiva que vivenciou com o companheiro.

Quando questionada sobre o parto, que ocorreu a termo, Gabriela descreve que insistiu para que este ocorresse de modo normal, mesmo tendo sentido muita dor. O menino, Pedro, nasceu primeiro com 3,095 kg e a menina, Fernanda, nasceu 15 minutos depois, com 2,700 kg, e nenhum dos bebês necessitou de internação neonatal.

Eixo II - O Puerpério. Gabriela refere que sentia muita falta do pai das crianças, principalmente neste período inicial, estando responsável, sozinha, por duas crianças, além do filho mais 
velho. Ela sempre contou com a ajuda da mãe/ avó e da irmã/tia, mas diz que faz questão de fazer quase tudo sozinha, dar banho, alimentar, brincar, fazer dormir.

Eu sempre troquei, sempre dei banho, em todos os dois, até hoje, eu faço tudo. Até esses dias ela brigou comigo porque ela queria dar banho, mas eu gosto, por mais que eu canse, eu gosto dessa função, primeiro dou banho em um e depois no outro, se um está mais agitado eu dou naquele que tá mais agitado primeiro, então assim vai, sempre gostei de cortar unha, sempre gostei de fazer tudo sabe.

Esse discurso pareceu um pouco contraditório, já que durante a observação ela solicitava ajuda da tia a todo instante, talvez porque estivesse dando atenção à pesquisadora. Outro fato que demonstra a contradição deste discurso foi observado durante a consulta médica de revisão das crianças, quando Gabriela entrou na sala somente com Fernanda, deixando Pedro, em evidente crise respiratória, aguardar do lado de fora da sala aos cuidados da tia (cena descrita de forma detalhada na sequência do texto).

Winnicott (1945/2012) afirma que uma mãe de gêmeos precisa dar conta de duas crianças ao mesmo tempo e este fato, por si só, traz como consequência a proximidade com o sentimento de fracasso, devendo esta mãe ficar satisfeita se conseguir fazer o melhor possível. Esse sentimento de fracasso assemelha-se a uma ferida narcísica materna, surgindo a partir do momento em que esta mãe de gêmeos se dá conta de que, por mais que se dedique, não conseguirá atender totalmente a demanda de ambos os bebês.

Gabriela amamentou os dois desde o início, sendo que ambos ganharam complemento de leite industrializado no hospital: Pedro sempre aceitou bem, mas Fernanda não gostava e vomitava. Pedro mamou com exclusividade até os quatro meses, depois começou a intercalar leite industrializado e chá de ameixa porque ele tinha constipação, até que a mamadeira não mais o saciava, que parecia muito guloso, segundo constatação da mãe. Assim, foi diversificando os alimentos oferecidos a ele, começando com frutas, sucos, conforme orientação do pediatra. Fernanda, aos nove meses, ainda não havia largado o peito e aceitava poucos tipos de alimentos, além do leite da mãe. Costuma fazer cara feia quando é oferecido outro alimento como comida, iogurte ou fruta.

Eixo III - Relação Mãe-Bebês. Os bebês dormem no quarto com a mãe, um na cama com ela e outro no berço. Geralmente é Fernanda quem fica no berço porque engatinha e já caiu da cama. A menina, além do peito, quer estar sempre no colo da mãe e, segundo ela, Fernanda é mais apegada a ela do que Pedro. Em função disso, a mãe fica bem mais tempo com Fernanda no colo, amamenta no peito, enquanto Pedro, de temperamento mais fácil, fica mais tempo no carrinho, come de tudo e aceita tudo com mais facilidade do que Fernanda. Segue um trecho do relato da observação para ilustrar esta cena:

Pedro quase não solicita a mãe, pediu colo apenas uma vez durante minha permanência na casa, parecendo estar com ciúme da irmã que estava há um bom tempo no colo. Gabriela então segura Pedro no colo e pede para a irmã pegar Fernanda que resmunga todo o tempo que a mãe está com o menino em seu colo. Ela aguenta a situação por alguns instantes e, em seguida coloca os dois no carrinho, mas a menina não fica, resmunga e consegue ir para o colo da mãe. O primeiro contato da pesquisadora com os participantes aconteceu durante a consulta pediátrica. Esta estava marcada para os dois bebês, porém Gabriela entrou na sala somente com Fernanda e logo o pediatra, que já a conhece, perguntou pelo outro filho, que estava na sala de espera com a tia. Então foi solicitado que entrassem todos juntos. Quando o pediatra viu o menino e observou sua respiração e seu resmungo, de imediato quis examiná-lo em primeiro lugar. Chamava atenção a dificuldade de respirar do menino que apresentava um forte episódio de crise de bronquite. O pediatra examinou Pedro, prescreveu medicação, tranquilizou a mãe e reforçou que, para o filho melhorar, o tratamento deveria ser seguido à risca, obedecendo sempre a medicação certa, o horário e quantidades deter- 
minados. Em seguida, encaminhou o menino à sala de enfermagem para realizar a primeira inalação já no posto de saúde, enquanto consultava a irmã.

Chama atenção o fato da mãe ter entrado na sala primeiro com a menina, que estava nitidamente bem de saúde e ter deixado o menino, em crise, esperando do lado de fora da porta, aos cuidados de outra pessoa. Além disso, observou-se que esta ficou com Fernanda no colo durante toda a consulta, enquanto o médico examinava o menino, sem se envolver diretamente nos cuidados com ele, tirar ou colocar roupas, deixando isso a cargo da tia e, quando este foi encaminhado para a inalação, também foi a tia quem o conduziu. A mãe parecia muito nervosa, dizendo que ficara a noite toda sem dormir porque Pedro estava com dificuldade de respirar, os olhos estavam cheios de lágrimas mas, ao mesmo tempo, esta não realizava os cuidados com ele durante a consulta, sem sequer tocá-lo.

O toque materno, de forma suficientemente boa, possibilita os processos de maturação no bebê, facilitando o desenvolvimento de confiança dele no mundo que o cerca (Winnicott, 1945/2012). Esta função de manipulação facilita a formação de uma parceria psicossomática na criança e a capacidade de sentir seu funcionamento corporal como um todo. Neste caso, o simples ato do toque ou da falta dele pode estar fazendo muita diferença para esta criança. Esse fato remete a uma possível falha no holding (Winnicott, 1960/1990), uma das capacidades da mãe suficientemente boa, que ao perceber o estado de dependência absoluta de seu bebê lhe ofereça condições suficientes de continência, além da manipulação do bebê que é considerada outra capacidade.

Parece bastante importante que a mãe possa se relacionar com os filhos, considerando cada um deles como um ser único, individualizado e não como "um bloco de dois filhos" (Machado, 1980). Ao buscar agir desta forma, cada criança poderá se individualizar de forma mais satisfatória. A comparação entre os gêmeos também é frequente por parte das pessoas de maneira geral e a mãe tem o papel de minimizar tais situações, que podem se tornar problemáticas, ressaltando as características de cada gêmeo. Desta forma, será mostrado tanto às crianças como às pessoas que fizerem tais comentários que as crianças têm méritos próprios e por motivos diferentes, sem tomar como base em padrões comparativos. Assim, situações de rivalidade e de comparações poderiam ser amenizadas.

Por vezes a mãe tem um discurso contraditório, relata que as suas expectativas quanto aos bebês é de querer que eles cresçam logo, parecendo querer pular as etapas, pois refere achar muito cansativo ter dois filhos bebês ao mesmo tempo mas, por outro lado, muito gratificante também. Essa ambivalência se reflete, inclusive no comportamento materno em relação aos filhos que se manifesta de modo diferente em cada criança. Se, por um lado, ela incentiva o menino a crescer, amadurecer, desmamando Pedro prematuramente, por outro lado incentiva a dependência de Fernanda, permitindo amamentação quase em tempo integral, como um bebê, reforçando a infantilização e dependência da menina. Além disso, chama a atenção que, durante a entrevista, após descrever fatos negativos ocorridos na gravidez ou até mesmo relatar dificuldades no cuidados com os filhos ela sempre concluía a frase afirmando: "apesar disso foi tranquilo", quando não se identificava nada de tranquilo em seu discurso.

Eixo IV - Sintomas Apresentados Pelos Bebês. Após a codificação dos dados do instrumento Symptom Check-List, os resultados apurados foram os seguintes: Pedro apresentou as categorias sono, alimentação, digestão, pele e comportamento com variações dentro da normalidade, apresentando alteração somente na categoria respiração que apontou sistema mãe-criança claramente disfuncional; Fernanda apresentou as categorias sono, digestão, respiração, pele e comportamento com variações dentro da normalidade porém, o item alimentação, aponta para sistema mãe-criança claramente disfuncional.

Desta forma, percebe-se então que os dois bebês apresentam indicadores de sintomas psicofuncionais: Pedro manifesta crises de bronquite respiratória, ficando dias com sintomas de crise respiratória como obstrução nasal, tosse forte com secreção, falta de ar; Fernanda, por sua vez, 
apresenta sintomas de dificuldades alimentares por não aceitar outros alimentos, querendo somente alimentar-se do leite materno. Sendo assim, as falhas maternas no oferecimento de um ambiente adequado ao estado de dependência absoluta e imaturidade do bebê, ocorrendo de modo sistemático e em intensidade acima do que pode ser suportado pelo bebê, podem fragilizá-lo e ocasionar a dificuldade de integração entre o soma e a psique (Winnicott, 1960/1990).

Neste sentido, a conflitiva materna pode se refletir na relação da mãe com os bebês e nos diferentes sintomas manifestados por eles. Alguns transtornos psicofuncionais manifestados pelos bebês podem se relacionar com situações difíceis vividas pelos pais ou pela mãe na gestação, parto ou puerpério (Peleg, Halaby, \& Whaby, 2006).

Pedro tem problemas respiratórios repetitivos desde os quatro meses, época em que também deixou de ser amamentado, e até o momento teve três episódios de crise, sendo o último descrito como o mais sério. Interessante notar que a manifestação dos sintomas de Pedro iniciaram justamente quando este deixou de ser amamentado pela mãe, aos quatro meses de idade. A sintomatologia manifestada por Pedro, justamente neste momento, pode estar relacionada a uma forma de expressar a sua dificuldade de separação em relação a mãe nesta fase ainda considerada precoce do desenvolvimento para o desmame. O sintoma se manifesta no campo respiratório, mas Pedro continua sob o controle materno, sem possibilidades de criar seu próprio espaço de subjetivação.

A opressão respiratória tem, então, um sentido simbólico inconsciente e pode representar a repetição de uma situação relacional através da angústia respiratória, impedindo que o bebê crie um espaço de subjetivação a partir da ausência materna e, portanto, crie defesas psíquicas. Assim, esta sintomatologia interfere negativamente no processo de crescimento, funcionando a favor da manutenção da dependência (Kreisler, 1978).

No que se refere à questão da amamentação, somente Pedro deixou de ser amamentado, enquanto Fernanda continua alimentando-se, quase que exclusivamente, do leite materno. A menina nunca aceitou conciliar a amamentação com outros alimentos próprios para sua faixa etária: não gosta de mamadeira, os alimentos oferecidos a ela como frutas, iogurte e comida costumam ser ingeridos em quantidades muito pequenas, uma ou duas colheradas, fazendo cara feia e manifestando desejo pelo peito da mãe. Conforme a mãe, Fernanda exige que tudo tem que ser do seu jeito, caso venha a ser contrariada fica bastante incomodada, atira coisas no chão e demonstra com facilidade seu descontentamento. Um trecho do relato da observação realizada ilustra esta atitude:

A tia ofereceu um bolacha para cada bebê, Fernanda pegou a bolacha, colocou na boca até a bolacha amolecer, e jogou-a no chão. Neste momento a mãe juntou a bolacha do chão, colocou sobre mesinha de centro e deu o peito para a menina mamar, tendo esta aceitado prontamente o peito.

Além disso, a ausência do pai, que poderia fazer este corte importante para o desenvolvimento saudável da criança, está ausente, pode vir a contribuir para o adiamento deste desmame. Nesta perspectiva, apesar da mãe se queixar, pode ser difícil para ela desmamar, romper essa proximidade. Deveria existir uma necessidade de separação por parte da mãe do corpo da criança e, caso isso não ocorra, pode demonstrar um certo prazer da mãe em manter a dependência da criança em relação a ela, ocorrendo falha na instalação da função paterna e na separação desta mãe. Esta falha decorre então da dificuldade de sustentação da mãe de um processo simbólico nas funções da criança (Pesaro, 2010).

Considerando os dados analisados até o momento, percebe-se que, da mesma forma que a dificuldade em favorecer o desmame pode evidenciar uma dificuldade materna em permitir que a criança se desenvolva e se diferencie desta mãe, o transtorno respiratório pode ter o mesmo sentido simbólico. Neste caso, a criança também é dependente da mãe, na medida em que esta a mantém sempre sob seu controle, impedindo que o bebê crie um espaço de subjetivação a partir da ausência materna, ocasionando falha na criação de defesas psíquicas (Kreisler, 1978). Desta forma, podemos pensar, também, que o desma- 
me do menino pode até ser entendido como um alívio para esta mãe, tendo a separação surgido muito mais por uma necessidade materna do que do bebê. Mesmo assim, a dependência do menino está mantida quando o sintoma dele se manifesta na área respiratória, continuando sob o controle materno.

\section{Considerações Finais}

A partir dos eixos propostos neste estudo, pode-se refletir a respeito da presença do sintoma na constituição dos bebês e a forma pela qual estes são vivenciados pela mãe através da relação mãe-bebês. A sintomatologia manifestada em bebês, numa fase precoce do desenvolvimento, surge trazendo desconforto aos pais e cuidadores, podendo, na maioria das vezes, não ser entendida como um sintoma psicológico, até mesmo pelo ferimento que este entendimento poderia causar ao narcisismo da mãe.

Da mesma forma, o estudo da expressão do sofrimento em bebês pela via corporal em função da precariedade de um aparato psíquico capaz de dar conta de expressar essas inconformidades de outra forma, ainda constituem uma lacuna na literatura atual. Porém, os sintomas psicofuncionais ocupam um lugar de destaque na vida das famílias que convivem com eles, em função dos atravessamentos que eles provocam na vida cotidiana.

Retomando o objetivo inicial deste estudo, percebe-se que a relação mãe-bebê em situação de gemelaridade configura-se de forma diferente e peculiar em relação a casos em que nasce apenas um bebê. Desta forma, pode-se inferir que cuidar de um bebê já se configura por si só uma tarefa que exige dedicação e entrega; quando se fala em dois bebês esta capacidade de entrega se multiplica. Neste caso, a possibilidade de falhas maternas também aumenta, devido à dificuldade que esta mãe certamente vai encontrar em suprir as necessidades de dois bebês simultaneamente. Os sintomas representam, então, uma expressão da relação mãe-bebê que, neste momento, não está servindo como um amparo psíquico adequado, necessário ao desenvolvimento saudável dos bebês. E os bebês, por sua vez, estão expostos a uma demanda com a qual ainda não sabem lidar, manifestando via corporal esta incapacidade.

Diante dessa situação, pode-se pensar na possibilidade da gemelaridade vir a se constituir como um dos fatores que pode aumentar as chances de surgimento de sintomas psicofuncionais. Neste caso, a mãe, por mais que se esforce, dificilmente conseguirá se colocar no lugar desses dois bebês ao mesmo tempo, suprindo suas necessidades de forma continente. Essa falha materna, pode ser inclusive descrita como "esperada" para casos de gemelaridade. Não se pretende, com isso, afirmar que a manifestação de sintomas psicofuncionais irá ocorrer de forma generalizada em todo contexto de gemelaridade ou multiparidade, apenas que as chances de sua ocorrência aumentam nestes casos.

Além disso, no caso abordado, esse fator de risco também se amplia devido à ausência do apoio paterno, tão destacada pela mãe em seu relato sobre seu período gestacional. Esta ausência paterna pode potencializar as chances de surgimento de falhas maternas e consequente risco ao desenvolvimento de sintomas psicofuncionais nos bebês. Caso estivesse presente, esta figura paterna poderia contribuir oferecendo apoio e segurança para esta mãe exercer seu papel, além de fazer cortes importantes na relação mãe-bebês, peculiares da função paterna, favorecendo o desenvolvimento saudável das crianças.

Não se pretende com essa colocação responsabilizar totalmente a mãe pelo que acontece em termos de saúde mental do bebê, mas sabe-se que a relação mãe bebê constitui-se numa interação delicada e de extrema importância para a formação psicológica do indivíduo. Desta forma, pode-se afirmar que a relação mãe-bebê pode influenciar, de maneira positiva ou negativa no desenvolvimento psicológico da criança.

Tendo em vista a importância de uma postura adequada dos pais de gêmeos, na maneira de tratá-los, contribuindo para uma relação mãe-bebê mais satisfatória, considera-se de grande importância a realização de trabalhos preventivos e de orientação familiar nesta área. Espera-se que esta pesquisa possa contribuir com estas 
questões, uma vez que a gemelaridade em uma perspectiva psicológica constitui-se num tema ainda pouco explorado na atualidade.

Desta forma, ampliar a compreensão acerca do funcionamento de uma tríade pode contribuir como medida preventiva e fornecer subsídios para profissionais de diversas áreas de atuação que trabalham com bebês e suas mães como escolas, hospitais, clínicas e psicoterapeutas da relação pais-bebê. Além disso, apesar das limitações do estudo, tentou-se aprofundar ao máximo a temática da pesquisa, a fim de se caracterizar como um trabalho sério, oportunizando a discussão dos dados levantados no caso, contribuindo com um tema ainda pouco aprofundado na literatura existente e demonstrando o caráter preventivo desta pesquisa, buscando ampliar o entendimento e evitando a cronificação da sintomatologia apresentada.

\section{Referências}

Bochernitsan, E. (2012) Percepção de pais e mães a respeito do comportamento de seus filhos gêmeos (Dissertação de mestrado, Pontifícia Universidade Católica do Rio Grande do Sul, Porto Alegre, RS, Brasil).

Careta, D. S. (2006). Análise do desenvolvimento emocional de gêmeos abrigados no primeiro ano de vida: Encontros e divergências sob a perspectiva winnicottiana (Dissertação de mestrado, Instituto de Psicologia, Universidade de São Paulo, SP, Brasil).

Conselho Federal de Psicologia. (2000). Resolução $n^{\circ}$ 16/2000 de 20/12/2000. Dispõe sobre a realização de pesquisa em Psicologia com seres humanos. Brasília, DF: Autor.

Cramer, B., \& Palácio-Espasa, F. (1993). Técnicas psicoterápicas mãe-bebê. Porto Alegre, RS: Artes Médicas.

Cunha, I. (2004). A mãe, o recém nascido de muito baixo peso e a interação: Uma nova perspectiva. In R. O. de Aragão (Ed.), O bebê, o corpo e a linguagem (pp. 211-223). São Paulo, SP: Casa do Psicólogo.

D’Onofrio, B. M., Slutske, W. S., Turkheimer, E., Emery, R. E., Harden, K. P., Heath, A. C., ...Martin, N. G. (2007). Intergenerational transmission of childhood conduct problems: A Children of
Twins Study. Archives General Psychiatry, 64(7), 820-829. doi:10.1001/archpsyc.64.7.820.

David, D. L., Azevedo, E. C., Russi, E. M. S., Berthoud, C. M. E., \& Oliveira, A. L. O. (2000). Tríade de contato íntimo: Apego entre mãe e filhos gêmeos. Revista Biociências, 6(1), 57-63.

Edelstein, T. M. (2000). A interação mãe-bebê: Os sintomas psicossomáticos e o pediatra. Revista Pediatria Moderna, 36(1-2), 70-74.

Golse, B. (2004). O bebê, seu corpo e sua psique: Explorações e promessas de um novo mundo (apego, psicanálise e psiquiatria perinatal). In R. O. de Aragão (Ed.), O bebê, o corpo e a linguagem (pp. 15-40). São Paulo, SP: Casa do Psicólogo.

Gorayeb, R. (1985). Psicopatologia infantil. São Paulo, SP: Editora Pedagógica e Universitária.

Jerusalinsky, J., \& Berlinck, M. T. (2008). Leitura de bebês. Estilos da Clínica, 24(13), 122-131.

Klein, M. (1982). Os Progressos da Psicanálise. Rio de Janeiro, RJ: Zahar Kon. (Original publicado em 1952)

Kreisler, L. (1978). A criança psicossomática. Lisboa, Portugal: Estampa.

Lebovici, S. (1999). As consultas psicoterápicas. In A. Guedeney \& S. Lebovici (Eds.), Intervenções psicoterápicas pais/bebê (pp. 63-71). Porto Alegre, RS: Artes Médicas.

Lucion, M. K., \& Escosteguy, N. (2011). Relação mãe-cuidadores de gemelares no primeiro ano após o nascimento. Revista Brasileira de Crescimento e Desenvolvimento Humano, 21(2), 207-318.

Machado, D. V. M. (1980). Meus filhos gêmeos. São Paulo, SP: Almed.

Marquez, I. S. M. A. B. (2008). Gêmeos, subjetividade e narcisismo: Especificidades interferentes (Dissertação de mestrado, Núcleo de Método Psicanalítico e Formações da Cultura, Pontifícia Universidade Católica de São Paulo, SP, Brasil).

Nedelec, J. L., Schwartz, J. A., Connolly, E. J., \& Beaver, K. M. (2012). Exploring the association between IQ and differential life outcomes: Results from a longitudinal sample of monozygotic twins. Temas em Psicologia, 20(1), 31-43.

Oliveira, A. (2002). Função materna e os fenômenos psicossomáticos: Reflexões a partir da asma infantil (Dissertação de mestrado, Universidade Federal do Rio Grande do Sul, Porto Alegre, RS, Brasil). 
Passos, C. S., \& Barbosa, A. J. G. (2011). Características de superdotação em um par de gêmeos monozigóticos. Psico-USF, 3(16), 317-326.

Peleg, O., Halaby, E., \& Whaby, E. N. (2006). The relationship of maternal separation anxiety and differentiation of self to children's separation anxiety and adjustment to kindergarten: A study in Druze families. Anxiety Disorders, 20, 973995.

Pesaro, M. E. (2010). Alcance e limites teórico-metodológicos da pesquisa multicêntrica de indicadores clínicos de risco ao desenvolvimento infantil (Tese de doutorado, Instituto de Psicologia, Universidade de São Paulo, SP, Brasil).

Pinto, E. B. (2004). Os sintomas psicofuncionais e as consultas terapêuticas pais/bebê. Estudos de Psicologia (Natal), 9(3), 451-457.

Robert-Tissot, C., Rusconi-Serpa, S., Bachman, J.-P., Besson, G., Cramer, B., Knauer, D., ...Palacio-Espasa, F. (1989). Le questionnaire "Sympton Check-List”. In S. Lebovici. P. Mazet, \& J.-P. Visier (Eds.), L'evaluation des interactions précoces entre le bébé et ses partenaires (pp. 179186). Paris: Eshel.

Robin, M., Corroyer, D., \& Casati, I. (1996). Childcare patterns of mothers of twins during the first year. Journal of Child Psychology and Psychiatry, 37(4), 453-460.

Singh, A. L., D’Onofrio, B. M., Slutske, W. S., Turkheimer, E., Emery, R. E., Harden, K. P., ...Martin, N. G. (2011). Parental depression and offspring Psychopathology: A Children of Twins study. Psychological Medicine, 41(7), 1385-1395.

Tavares, M. E. B. P. (2007). Situações triangulares em gêmeos durante o primeiro ano de vida: Conjecturas sobre o complexo de Édipo (Tese de doutorado, Instituto de Psicologia, Universidade de São Paulo, SP, Brasil).
Tenenbojm, E., Rossin,S., Estivill, E., Segarra, F., \& Reimão, R. (2010). Causas de insônia nos primeiros anos de vida e repercussão nas mães: Atualização. Revista Paulista Pediatria, 28(2), 221-226.

Vendruscolo, J. F., Bolzan, G. M., Crestani, A. H., Souza, A. P. R., \& Moraes, A. B. (2012). A relação entre o aleitamento, transição alimentar e os indicadores de risco para o desenvolvimento infantil. Distúrbios da Comunicação, 24(1), 4152.

Vieira, A. O. M., \& Uchoa, A. B. (2010). Cultura, crenças e práticas de socialização de gêmeos monozigóticos. Psicologia em Revista, 16(3), 575-593.

Wendland, J. (2001). A abordagem clínica das interações pais-bebê: Perspectivas teóricas e metodológicas. Psicologia: Reflexão e Crítica, 14(1), 45-56.

Winnicott, D. W. (1990). Teoria do relacionamento paterno-infantil (I. C. S. Ortiz, Trad.). In D. W. Winnicott, $O$ ambiente e os processos de maturação (pp. 38-54). Porto Alegre, RS: Artes Médicas. (Original publicado em 1960)

Winnicott, D. W. (2012). A criança e seu mundo. Rio de Janeiro, RJ: LTC. (Original publicado em 1945)

Yin, R. K. (2005). Estudo de caso: Planejamento e métodos. Porto Alegre, RS: Bookman.

Zamberlan, M. A. T. (2002). Interação mãe-criança: Enfoques teóricos e implicações decorrentes de estudos empíricos. Estudos de Psicologia (Natal), 7(2), 399-406. 